\title{
Detrusor overactivity in diabetic and non-diabetic patients: Is there a difference?
}

\author{
Tomasz Golabek, Eamonn Kiely, Barry O’Reilly \\ Cork University Hospital (TG,EK) and Maternity Hospital (BOR), Cork, Republic of Ireland
}

\section{ABSTRACT}

Purpose: To compare urodynamic characteristics in patients with idiopathic detrusor overactivity (IDO) with those of an age matched cohort with diabetes mellitus (DM) and detrusor overactivity (D0). Secondly, to determine whether urodynamic features could help distinguish these two groups of patients.

Materials and Methods: Urodynamic data was collected on 58 female patients; 29 with IDO and 29 with DM and detrusor overactivity. Eight urodynamic parameters were selected for analysis: amplitude of the first overactive contraction (AOFC), the volume at the first contraction, cystometric capacity, maximal detrusor pressure, maximal flow rate, voiding pressure at maximal flow, voided volume and postvoid residual (PVR) urine volume. Finally, sensitivity analysis for distinguishing urodynamic parameters between studied groups was performed.

Results: AOFC, volume at AOFC and maximal detrusor pressure were statistically greater in diabetic patients, compared with the non-diabetic group of women $(16.00 \mathrm{~cm}$

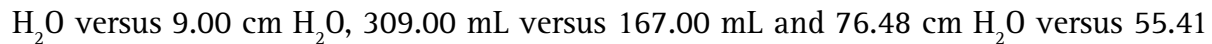
$\mathrm{cm} \mathrm{H}_{2} \mathrm{O}$ respectively). A specificity of $72.41 \%$ and positive predictive value of $71.43 \%$ were achieved for AOFC with cutoff value of $12 \mathrm{~cm} \mathrm{H}_{2} 0$. These parameters were further improved with cutoff value of $258 \mathrm{~mL}$ for volume at AOFC and were $75.86 \%$ and 73.08\% respectively.

Conclusions: Certain urodynamic parameters in diabetic female patients with DO are shown to be significantly different than those in women with IDO. Further prospective study should provide additional information about the pathogenesis and progression of DO in diabetic patients as well as the validity of diabetic screening in patients with IDO.
ARTICLE INFO

Key words:

Diabetes mellitus;

Urodynamics; Urothelium

Int Braz J Urol. 2012; 38: 652-60

Submitted for publication:

March 13, 2012

Accepted after revision: July 27, 2012

\section{INTRODUCTION}

Diabetes mellitus (DM) has been shown to alter vesicourethral function in a number of ways, from decreased detrusor contractility to bladder overactivity present in up to $61 \%$ of diabetic patients (1).

The etiology of DO in diabetic patients is not fully understood and is most likely multifactorial. Both central and peripheral mechanisms have been implicated; namely, diabetic cerebral vasculopathy and peripheral nerve stimulation as well as changes in the detrusor muscle and urothelium (2-4).

Idiopathic overactive bladder can be observed in approximately $17 \%$ of the general adult population; however, the incidence of ID0 is not known $(5,6)$. The pathophysiology of idiopathic bladder overactivity is not clear. Although it is defined as DO in the absence of a definite cause, some authors have reported on the presence of neurological signs (7). Despite the fact that not 
all individuals with idiopathic overactive bladder require treatment, the condition has been shown to significantly impact on patient quality of life; often leading to isolation and depression $(8,9)$.

Given that lower urinary tract symptoms are not disease specific and it is still unclear what can initiate ID0, the aim of the present study was to determine if there are differences in urodynamic characteristics between patients with overactive bladder secondary to diabetes mellitus and patients with overactive bladder without diabetes or any known neurologic abnormalities. Sensitivity and specificity analyses were performed to assess their ability to predict diabetic overactive bladder according to various urodynamic parameters.

\section{MATERIALS AND METHODS}

Urodynamic data of all female patients who underwent urodynamic studies in Departments of Urology and Urogynaecology of the Cork University Hospital over the period 2004 and 2008 were reviewed retrospectively. Patients with objective signs of overactive bladder during the study, defined as an involuntary rise in detrusor pressure of greater than $5 \mathrm{~cm} \mathrm{H}_{2} \mathrm{O}$ during filling associated with urgency or bladder fullness, were selected. Then, medical charts of all selected patients were reviewed and a database with patients' blood glucose levels and HBA1c were searched. Only patients with a known diagnosis of diabetes mellitus were included in the database of patients with DM while non-neurogenic patients with no history of diabetes and normal glucose levels were selected for the study in the idiopathic bladder overactivity group.

Exclusion criteria included patients with urodynamic evidence of bladder outlet obstruction, defined as maximum flow rate less than 12 $\mathrm{mL} / \mathrm{min}$. and detrusor pressure at maximum flow of more than $45 \mathrm{~cm} \mathrm{H}_{2} \mathrm{O}$. Those with presence of concurrent neurologic disorders such as stroke, Parkinson disease, spinal cord injury, and multiple sclerosis were also excluded. Lastly, patients with medical conditions that could interfere with voiding function such as prior pelvic surgery, anterior pelvic prolapse of stage 2 or greater (BadenWalker) or those on medication that could affect bladder function such as diuretics, calcium channel blockers and narcotics were excluded from the study. A total of 58 patients fulfilled the inclusion criteria and of these, 29 were diabetic with DO and 29 patients had IDO.

Urodynamic studies were performed by two experienced urodynamic nurses using the Solar Silver (MMS, Enschede, The Netherlands) and Dantec Menuet (Medtronic Functional Diagnostics A/S, Slovlunde, Denmark) urodynamic measurement systems. A standard protocol was employed in accordance with the guidelines established by the International Continence Society (ICS) (10). All anticholinergic medications were stopped at least 72 hours before study and all patients who underwent urodynamic evaluation had confirmed negative urinalysis findings prior the procedure. The studies were performed with patients in the seated position. Urinary bladders were filled at $50 \mathrm{~mL} /$ min. rate using room temperature sterile saline. A dual lumen $8 \mathrm{~F}$ vesical catheter and $4.5 \mathrm{~F}$ rectal catheter were used. Eight urodynamic parameters were selected for analysis: amplitude of the first contraction (AOFC), the volume at the first contraction, cystometric capacity, maximal detrusor pressure (Pdetmax), maximal flow rate (Qmax), voiding pressure at maximal flow (PdetQmax), voided volume and postvoid residual (PVR) urine volume. Also Bladder Voiding Efficiency (BVE), an index that defines bladder voiding function, was calculated as described previously by Abrams, and then statistically analyzed (11). BVE was obtained by the formula: $B V E=100 \% \mathrm{x}$ voided volume/ (voided volume+PVR).

All measurements were repeated three times by the same investigator to avoid bias.

Statistical analyses were performed using SPSS package version 11.5. The Shapiro-Wilk test was used to examine for normal distribution. Results were presented as mean values \pm standard deviation when data were normally distributed, otherwise as median, 25th and 75th percentile (AOFC, volume at AOFC, PVR and BVE). Nonparametric t test and Mann-Whitney $U$ tests were applied as appropriate.

Multiple logistic regression analysis using the forward stepwise regression with Wald test method was subsequently applied to select 
a set of variables distinguishing diabetic patients with DO from ID0.

The associations between age and urodynamic parameters were examined using Pearson's correlation analyses for normally distributed data, otherwise Spearman's rank correlation coefficient was used. Sensitivity and specificity analyses for the ability to predict diabetic DO on the basis of AOFC, volume at AOFC and Pdetmax were also performed. For all statistical tests $\mathrm{p}<0.05$ was considered significant.

\section{RESULTS}

A total of 97 urodynamic studies were carried out on female diabetic patients referred from urology or urogynaecology departments in our university hospital over the period 2004 -2008. Of these, 41 women had DO. Strict inclusion criteria were fulfilled only in 29 patients. Three patients had type $1 \mathrm{DM}$ and 26 type 2 of at least 3 years duration. Their average age was $53.84 \pm 16.0$ years. Average HBA1c level measured over one year preceding urodynamics was determined in 26 patients and was $6.05 \pm 2.38 \%$ (5.1-12.1\%). Five patients had HBA1c level checked after or more than a year before the study. In 15 diabetic women (51\% of total), the major reported complaints were frequency and urge incontinence; 8 cases reported urgency without incontinence $(28 \%)$; mixed urinary incontinence was the main problem in a further $4(14 \%)$ and recurrent bladder infections in 2 more cases (7\%).

Urodynamic data were also collected from 29 female patients complaining of symptoms suggestive $\mathrm{OAB}$ and who had no previous history of diabetes mellitus or neurological disorder and who were referred for evaluation of their lower urinary tract. The average age of this group was $50.42 \pm$ 20.23years. The most common symptoms of women with ID0 were urge incontinence in 11 cases (38\%), mixed urinary incontinence in 7 (24\%), urgency without incontinence in 5 (17\%), voiding symptoms (hesitancy, dribbling, incomplete emptying) in $4(14 \%)$ and stress incontinence in 2 cases (7\%).

Table- 1 shows characteristics of the groups studied and comparison of the analyzed urodynamic parameters between the two investigated groups. Greater amplitude of the first overactive contraction was observed in patients with DM than in females with IDO $\left(18.31 \mathrm{~cm} \mathrm{H}_{2} \mathrm{O}\right.$ versus $11.03 \mathrm{~cm}$ $\mathrm{H}_{2} \mathrm{O}$ ). Also, these patients had a stronger maximal detrusor contraction compared to those with IDO (76.48 $\mathrm{cm} \mathrm{H}_{2} \mathrm{O}$ versus $55.41 \mathrm{~cm} \mathrm{H}_{2} \mathrm{O}$ ). The initial contraction occurred later during the filling phase in diabetic women than in those patients with IDO (333.83 $\mathrm{mL}$ versus $208.72 \mathrm{~mL}$ ).

The remaining analyzed parameters were not statistically different in both groups under investigation. Also, BVE was within the normal range and showed no statistical difference in both diabetic DO and IDO group.

Multiple logistic regression analysis using the forward stepwise regression with Wald test method showed that a set of three urodynamic parameters (AOFC, volume at AOFC and Pdetmax) distinguished diabetic overactive bladder from IDO. AOFC showed to be the most independently aspect with ability to differ diabetic overactive bladder and ID0 with classification accuracy of 70.7\%. The combination of AOFC, volume at AOFC and Pdetmax improved accuracy to $79.3 \%$.

To examine associations between age and parameters distinguishing diabetic DO and IDO, Pearson's correlation analyses or Spearman's rank correlation coefficient were performed. No relationship between age and parameters under investigation was found.

Since AOFC, volume at AOFC and maximal detrusor pressure between diabetic patients and women with IDO differed significantly, cutoff values were established to evaluate sensitivity, specificity, positive (PPV) and negative predictive values (NPV). A cutoff value of $12 \mathrm{~cm} \mathrm{H}_{2} \mathrm{O}$ or greater for AOFC produced sensitivity, specificity and positive predictive value of $68.97 \%, 72.41 \%$ and $71.43 \%$ respectively. Whereas analyses of using a cutoff value of 258 or greater for volume at AOFC resulted in further improvement of specificity and PPV (75.86\% and 73.08\% respectively). Evaluation of maximal detrusor pressure did not led to reasonable results (Table-2).

\section{DISCUSSION}

In this study we analyzed and compared bladder function in 29 female patients with dia- 
Table 1 - Characteristics of the groups and comparison of urodynamic parameters and index of bladder voiding function in diabetic patients with DO and IDO.

\begin{tabular}{|c|c|c|c|}
\hline Parameter & $\begin{array}{l}\text { Diabetic patients with D0 } \\
\qquad(\mathrm{n}=29)\end{array}$ & $\begin{array}{l}\text { Patients with idiopathic DO } \\
\qquad(\mathrm{n}=29)\end{array}$ & P Value \\
\hline Age (years) & $53.84 \pm 16.00$ & $50.42 \pm 20.23$ & 0.619 \\
\hline HBA1C & $6.05 \pm 2.38$ & $\mathrm{~N} / \mathrm{A}$ & $\mathrm{N} / \mathrm{A}$ \\
\hline \multicolumn{4}{|l|}{ Major symptoms } \\
\hline Frequency and urge incontinence & $51 \%$ & $38 \%$ & $\mathrm{~N} / \mathrm{A}$ \\
\hline Urgency without incontinence & $28 \%$ & $17 \%$ & $\mathrm{~N} / \mathrm{A}$ \\
\hline Mixed urinary incontinence & $14 \%$ & $24 \%$ & $\mathrm{~N} / \mathrm{A}$ \\
\hline Stress incontinence & $0 \%$ & $7 \%$ & $\mathrm{~N} / \mathrm{A}$ \\
\hline Voiding symptoms & $0 \%$ & $14 \%$ & $\mathrm{~N} / \mathrm{A}$ \\
\hline Recurrent UTIs & $7 \%$ & $0 \%$ & $\mathrm{~N} / \mathrm{A}$ \\
\hline $\mathrm{AOFC}\left(\mathrm{cm} \underline{\mathrm{H}}_{2} \underline{0}\right)$ & $16.00(11.00 ; 22.00)$ & $9.00(6.5 ; 15.00)$ & $0.001\left(^{*}\right)$ \\
\hline Volume at $\mathrm{AOFC}(\mathrm{mL})$ & $309.00(208.00 ; 496.00)$ & $167.00(84.00 ; 277.00)$ & $0.001\left(^{*}\right)$ \\
\hline Cystometric capacity $(\mathrm{mL})$ & $447.00 \pm 118.95$ & $432.66 \pm 183.75$ & 0.828 \\
\hline Pdetmax $\left(\mathrm{cm} \underline{\mathrm{H}}_{2} \underline{0}\right)$ & $76.48 \pm 32.45$ & $55.41 \pm 20.95$ & $0.010\left(^{*}\right)$ \\
\hline$Q \max (\mathrm{mL} / \mathrm{s})$ & $22.331 \pm 9.99$ & $25.890 \pm 12.36$ & 0.304 \\
\hline$P \operatorname{det} Q_{\max }\left(\mathrm{cm} \underline{H}_{2} \underline{0}\right)$ & $40.69 \pm 22.00$ & $33.07 \pm 17.534$ & 0.194 \\
\hline Voided Volume (mL) & $414.59 \pm 154.87$ & $401.17 \pm 201.30$ & 0.703 \\
\hline PVR (mL) & $5.00(0.00 ; 35.00)$ & $2.00(0.00 ; 30.00)$ & 0.483 \\
\hline BVE\% & $98.54(86.65 ; 100.00)$ & $99.57(92.87 ; 100.00)$ & 0.663 \\
\hline
\end{tabular}

${ }^{*}$ Statistically significant.

Key: HBA1C = glycosylated haemoglobin level, $\mathbf{N} / \mathbf{A}=$ not applicable; UTIs = urinary tract infections, $\mathbf{D O}=$ detrusor overactivity; IDO = idiopathic

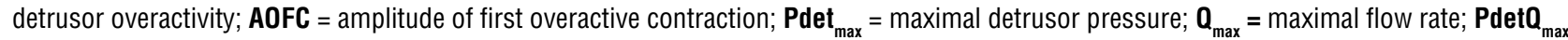
= detrusor pressure at maximal flow; PVR = postvoid residual (urine volume); BVE = Bladder Voiding Efficiency.

All data are presented as mean \pm standard deviation except AOFC, Volume at AOFC, PVR and BVE which are expressed as median, 25th percentile (first figure in the brackets) and 75th percentile (second figure in the brackets).

betic cystopathy and 29 female patients with DO without DM or known neurological abnormalities. All of them were referred from urology or urogynaecology departments at our university hospital for an evaluation of lower urinary tract function. In our patient population, we demonstrated that the amplitude of the first detrusor contraction was greater in diabetic patients than in women without known glycaemic and neurologic abnormalities. Similarly, the maximum detrusor pres- sure generated was higher in the group of patients with DM. These findings may suggest less controllable symptoms of DO in diabetic individuals. Although comparable data on the lower urinary tract symptoms between patients with ID0 and diabetic DO are not available, a recent large observational study reported on an increase in urge incontinence frequency in women with DM (12). This symptom has been shown to have a profound effect on patients' quality of life $(13,14)$. 
Table 2 - Sensitivity, specificity, positive predictive value and negative predictive value for AOFC, Volume at AOFC and Pdetmax at developed cutoff values.

\begin{tabular}{|c|c|c|c|c|}
\hline Parameter & Sensitivity (\%) & Specificity (\%) & PPV (\%) & NPV (\%) \\
\hline $\mathrm{AOFC}>12 \mathrm{~cm} \underline{\mathrm{H}}_{2} \underline{0}$ & 68.97 & 72.41 & 71.43 & 70.00 \\
\hline Volume at AOFC $>258 \mathrm{~mL}$ & 65.52 & 75.86 & 73.08 & 68.75 \\
\hline Pdetmax $>63 \mathrm{~cm}_{2} \underline{\underline{O}}$ & 62.07 & 65.52 & 64.29 & 63.33 \\
\hline
\end{tabular}

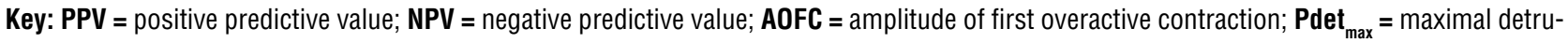
sor pressure; $\mathbf{P d e t}_{\max }=$ detrusor pressure at maximal flow; $\mathbf{P V R}=$ postvoid residual (urine volume)

Interestingly in our study, detrusor contractions occurred later during filling in the DM group than in patients with IDO. However, PVR in both patients with diabetes and DO and IDO was not increased thus functional capacity in diabetic patients was not reduced and bladder contractions were occurring at different intervals in both investigated groups.

These findings are different from other reports that noticed increased PVR and decreased functional capacity in diabetic DO individuals $(2,15)$; but similar to those suggesting that conditions affecting nervous system may induce stronger overactive contractions at higher volume (16).

The greater amplitude of the first detrusor contraction, volume at first contraction, and maximum detrusor pressure observed in patients with diabetes can be explained by diuresis-induced bladder wall tissue remodeling and neuropathy. Several studies in the past have demonstrated that the high rate of bladder filling during cystometry may result in an increase in intravesical pressure and threshold volume (17-19). In addition, such non-physiological filling rates may mechanically damage the afferent limb of the micturition reflex resulting in the later generation of action potentials and, consequently, an urge to void at volumes which are larger then normal. Although the mechanisms involved in triggering bladder tissue hypertrophy and hyperplasia in patients with diabetes are not very clear, it seems that a high filling rate is a primary factor in the stimulation of hyperplasia of bladder smooth muscle, urothelium and connective tissue $(20,21)$. An increase in bladder weight is also related to alterations in bladder volume as well as the rate of stretch of the bladder wall, both caused by polyuria, a consequence in itself of diabetes (22). Increases in fluid output likely contribute to faster and greater increases in bladder weight in diabetic patients with DO than in patients with idiopathic detrusor overactivity.

Both peripheral autonomic neuropathy and central nervous system dysfunction due to cerebral vasculopathy are implied in the aetiology of D0 in diabetic patients $(2,23)$. However, this kind of diabetic bladder dysfunction can also be present in the absence of CNS lesions (2). In our study, patients with history of stroke were excluded, thus peripheral pathology as the cause of development of DO need to be considered. In addition, alterations in bladder innervation, the bladder smooth muscle cells and urothelium have been proposed to be involved in early stages of diabetic bladder dysfunction (4). M2 receptors up-regulation with partial autonomic denervation leading to the decreased cholinergic transmission are involved in the aetiology of DO with altered contractility in early stages of diabetic bladder dysfunction (24).

Although the chronology of bladder dysfunction in DM and its correlation with diabetic control is not fully known, one group led by Rundles investigated the initial manifestation of the diabetic neurogenic bladder (25). In their series, $83 \%$ of diabetic patients with neuropathy had an abnormal cystometrogram and enlarged bladder indicating neurogenic bladder. However, most of them had no residual urine. This differs from advanced diabetic neurogenic bladder with paralysis. These findings were consistent with those in recent reports garnered from laboratory animals (21). 
Up to $61 \%$ of patients with diabetic bladder dysfunction have DO (1). Currently diagnostic evaluation of patients with IDO does not include determination of diabetes (26). Although routine assessment prior to urodynamics includes questions about DM there is no additional check for diabetes except for urine testing for glycosuria. However, urine testing for glycosuria as screening for DM is not recommended particularly in patients with type 2 diabetes, because of the low sensitivity of the test (27-29). Glucose tolerance test and fasting glucose measures have been the standard tests for screening and diagnosing of diabetes mellitus. Recently hemoglobin A1c testing for the diagnosis of type 2 diabetes has been recommended (30).

The utility of fasting glucose and HBA1c measurements have not yet been evaluated in patients with IDO.

In our study we used a cutoff value of $12 \mathrm{~cm} \mathrm{H}_{2} \mathrm{O}$ for the amplitude of the first overactive contraction in diabetic patients with DO. Specificity was $72.41 \%$, however positive predictive value was $71.43 \%$. These parameters were further improved when analyzed for volume at AOFC. Using a cutoff value of $258 \mathrm{~mL}$ specificity and PPV were $75.86 \%$ and $73.08 \%$ respectively. Therefore, we suggest diabetic screening in the IDO patient with greater amplitude and bladder volume at the first overactive contraction.

Our study was a retrospective, two-unit analysis of patients and as such is subjected to biases and limitations that surround these study types. Data obtained from medical charts may not have revealed undiagnosed neurologic condition which could affect all women, however to our knowledge none had been diagnosed at this point. In addition, study participants may not be a representative cohort from the greater community; thus limiting the ability to generalize findings. Finally, amplitude of the first overactive contraction is not an ideal parameter quantifying detrusor overactivity as it may be affected by various factors during bladder filling. Although all urodynamic studies were performed under the same conditions and in accordance with the strict guidelines established by the ICS to maintain their objectivity, accuracy and reliability it is possible that some discrete factors could affect AOFC. However, combining AOFC, volume at AOFC and Pdetmax improved accuracy for identifying diabetic female with DO and minimized potential bias. Further prospective study in a larger cohort of patients would be useful to stratify certain subgroups based on type and duration of diabetes, symptom levels and glycaemic control.

\section{CONCLUSIONS}

Certain urodynamic parameters are important for the detection of diabetes-related DO. It seems that stronger overactive contractions in the presence of larger threshold volume at which they occur characterize the DO in diabetic female patients and suggest different pathogenesis then that involved in IDO. Also diabetic screening of women with IDO and greater amplitude of the first overactive contraction may have a role in identifying patients who do not have a true IDO.

Further prospective studies will provide additional information about pathogenesis and progression of DO in diabetic patients as well as validity of diabetic screening in patients with IDO who have high amplitude and volume at first overactive contractions. Comparison of urodynamic parameters in diabetic patients with and without urodynamically demonstrable DO as well as in patients with neurogenic detrusor overactivity may provide important information on chronology of bladder dysfunction in DM and mechanisms involved in the development of diabetic cystopathy.

\section{ABBREVIATIONS}

AOFC = amplitude of first overactive contraction

$\mathrm{BE}=$ bladder voiding efficiency

$\mathrm{CNS}=$ the central nervous system

$\mathrm{DM}=$ diabetes mellitus

DO = detrusor overactivity

HBA1c = glycosylated haemoglobin level

IDO = idiopathic detrusor overactivity

ICS = The International Continence Society

$\mathrm{NPV}=$ negative predictive value

Pdet $_{\max }=$ maximal detrusor pressure

PdetQ $_{\text {max }}=$ detrusor pressure at maximal flow

$\mathrm{PPV}=$ positive predictive value

PVR = postvoid residual (urine volume)

$\mathrm{Q}_{\max }=$ maximal flow rate 


\section{ACKNOWLEDGEMENTS}

We thank Dolores 0'Donnell, clinical nurse specialist at CUH and Elaine Dilloughery, continence nurse specialist at CUMH for performing the urodynamic studies.

\section{CONFLICT OF INTEREST}

None declared.

\section{REFERENCES}

1. Starer P, Libow L: Cystometric evaluation of bladder dysfunction in elderly diabetic patients. Arch Intern Med. 1990; 150: 810-3.

2. Yamaguchi $\mathrm{C}$, Sakakibara R, Uchiyama T, Yamamoto T, Ito T, Liu Z, et al.: Overactive bladder in diabetes: a peripheral or central mechanism? Neurourol Urodyn. 2007; 26: 807-13.

3. Lee WC, Wu HP, Tai TY, Yu HJ, Chiang PH: Investigation of urodynamic characteristics and bladder sensory function in the early stages of diabetic bladder dysfunction in women with type 2 diabetes. J Urol. 2009; 181: 198-203.

4. Yoshimura N, Chancellor MB, Andersson KE, Christ GJ: Recent advances in understanding the biology of diabetesassociated bladder complications and novel therapy. BJU Int. 2005; 95: 733-8.

5. Stewart WF, Van Rooyen JB, Cundiff GW, Abrams P, Herzog $A R$, Corey $R$, et al.: Prevalence and burden of overactive bladder in the United States. World J Urol. 2003; 20: 327-36.

6. Milsom I, Abrams P, Cardozo L, Roberts RG, Thüroff J, Wein AJ: How widespread are the symptoms of an overactive bladder and how are they managed? A population-based prevalence study. BJU Int. 2001; 87: 760-6. Erratum in: BJU Int 2001; 88: 807.

7. Ahlberg J, Edlund C, Wikkelsö C, Rosengren L, Fall M: Neurological signs are common in patients with urodynamically verified "idiopathic" bladder overactivity. Neurourol Urodyn. 2002; 21: 65-70.

8. Brown JS, Posner SF, Stewart AL: Urge incontinence: new health-related quality of life measures. J Am Geriatr Soc. 1999; 47: 980-8.

9. Dugan E, Cohen SJ, Bland DR, Preisser JS, Davis CC, Suggs PK, et al.: The association of depressive symptoms and urinary incontinence among older adults. J Am Geriatr Soc. 2000; 48: 413-6.

10. Abrams P, Cardozo L, Fall M, Griffiths D, Rosier P, Ulmsten $U$, et al.: The standardisation of terminology of lower urinary tract function: report from the Standardisation Sub-committee of the International Continence Society. Neurourol Urodyn. 2002; 21: 167-78.
11. Abrams P: Bladder outlet obstruction index, bladder contractility index and bladder voiding efficiency: three simple indices to define bladder voiding function. BJU Int. 1999; 84: 14-5.

12. Jackson RA, Vittinghoff E, Kanaya AM, Miles TP, Resnick HE, Kritchevsky SB; et al.: Urinary incontinence in elderly women: findings from the Health, Aging, and Body Composition Study. Obstet Gynecol. 2004; 104: 301-7.

13. Kobelt G, Kirchberger I, Malone-Lee J: Review. Quality-of-life aspects of the overactive bladder and the effect of treatment with tolterodine. BJU Int. 1999; 83: 583-90.

14. Patel AS, O'Leary ML, Stein RJ, Leng WW, Chancellor MB, Patel SG, et al:: The relationship between overactive bladder and sexual activity in women. Int Braz J Urol. 2006; 32: 7787.

15. Lee WC, Wu HP, Tai TY, Liu SP, Chen J, Yu HJ: Effects of diabetes on female voiding behavior. J Urol. 2004; 172: 989-92.

16. Lemack GE, Frohman EM, Zimmern PE, Hawker K, Ramnarayan P: Urodynamic distinctions between idiopathic detrusor overactivity and detrusor overactivity secondary to multiple sclerosis. Urology. 2006; 67: 960-4.

17. Hamaide AJ, Verstegen JP, Snaps FR, Onclin K, Balligand MH: Validation and comparison of the use of diuresis cystometry and retrograde filling cystometry at various infusion rates in female Beagle dogs. Am J Vet Res. 2003; 64: 574-9.

18. Klevmark B: Volume threshold for micturition. Influence of filling rate on sensory and motor bladder function. Scand J Urol Nephrol Suppl. 2002; 210: 6-10.

19. Robertson AS, Griffiths CJ, Ramsden PD, Neal DE: Bladder function in healthy volunteers: ambulatory monitoring and conventional urodynamic studies. Br J Urol. 1994; 73: 242-9.

20. Saito M, Longhurst PA, Murphy M, Monson FC, Wein AJ, Levin RM: Effect of slow and rapid cystometry on in vitro rat urinary bladder DNA synthesis. Gen Pharmacol. 1994; 25: 1021-5.

21. Daneshgari F, Liu G, Imrey PB: Time dependent changes in diabetic cystopathy in rats include compensated and decompensated bladder function. J Urol. 2006; 176: 380-6.

22. Liu G, Daneshgari F: Temporal diabetes- and diuresis-induced remodeling of the urinary bladder in the rat. Am J Physiol Regul Integr Comp Physiol. 2006; 291: R837-43.

23. Rapidi CA, Karandreas N, Katsifotis C, Benroubi M, Petropoulou K, Theodorou C: A combined urodynamic and electrophysiological study of diabetic cystopathy. Neurourol Urodyn. 2006; 25: 32-8.

24. Wein AJ: Lower urinary tract dysfunction in neurological imaging and disease. In: Cambell-Walsh Urology, 9th ed. Edited by AJ Wein, LR Kavoussi, AC Novik, AW Partin and CA Peters. Philadephia: WB Saunders Co 2007; pp. 2011-45.

25. Rundles RW: Diabetic neuropathy. General review with report of 125 cases. Medicine. 1945; 24:111-60.

26. Ouslander JG: Management of overactive bladder. N Engl J Med. 2004; 350: 786-99. 
27. Friderichsen B, Maunsbach M: Glycosuric tests should not be employed in population screenings for NIDDM. J Public Health Med. 1997; 19: 55-60.

28. No authors listed: Diabetes mellitus. Report of a WHO Study Group. World Health Organ Tech Rep Ser. 1985; 727: 1-113.
29. Lawton J, Peel E, Douglas M, Parry 0: 'Urine testing is a waste of time': newly diagnosed Type 2 diabetes patients' perceptions of self-monitoring. Diabet Med. 2004; 21: 1045-8.

30. International Expert Committee: International Expert Committee report on the role of the $\mathrm{A} 1 \mathrm{C}$ assay in the diagnosis of diabetes. Diabetes Care. 2009; 32: 1327-34.

Correspondence address:

Dr. Tomasz Golabek, Department of Urology, Cork University Hospital, Wilton, Cork

Republic of Ireland Fax: + 021 492-1323

E-mail: elementare@op.pl 


\section{EDITORIAL COMMENT}

This is a nice, small study that deserves some considerations. The authors described urodynamic over activity particularities related to diabetes mellitus. In my opinion, more important than isolated numbers themselves, are the implications of such increasing data relating diabetes mellitus and urinary tract disorders.

We cannot forget the potential impact that systemic illness and its repercussions can lead to the urinary tract, and how its treatment could change things, over time. Although small, the numbers showed by the authors bring some questions in mind.

1. Diabetic patients in the study have had this diagnosis for at least, 3 years, but we do not know for how long, exactly, they have this condition. Probably, the fact that all others variables analyzed did not show statistical differences when compared to the control group, can be related to the fact that these patients don't have very lasting disease timing.

Clinical and experimental data confirm that detrusor over activity, both neurogenic and myogenic can be present in diabetic neuropathic bladders. Moreover: these findings are normally seem in earlier stages of the disease, whereas detrusor under activity appears to be linked to later stages of DM. (Does diabetes mellitus-induced bladder remodeling affect lower urinary tract function? Kirschner-Hermanns R, Daneshgari F, Vahabi B, Birder L, Oelke M, Chacko S.Neurourol Urodyn. 2012; 31(3): 35964. ICI-RS 2011). So, if the sample was bigger, and the lasting time of the disease analyzed, could the results associated to the other variables be different? This is a nice question to be answered, in the future. The same doubt can be extended to the glycemic control. Do the patients that have betters long lasting glycemic controls show less symptoms and urodynamic changes over time? If so, could we act as prophylactic agents of chronic urinary tract disturbances in such group?

2. The authors also raise the question about diabetic screening of patients with IDO and some urodynamic findings. Thinking on the clinical nature of the diagnosis of hyperactive bladder, I agree with such screening but I rather do it on all patients with this clinical picture, instead of doing it only in patients submitted to such study with critical findings. It looks like the practical application of an increasing body of knowledge on the complex etiology of urinary tract disorders.

I expect that more studies like this can help us to understand the real relationship of chronic illness like diabetes and urinary tract disorders in order to open new perspectives of, perhaps, prophylactic treatments in the future.

\footnotetext{
Dr. Caio Cintra Assistant Professor Department of Urology FMABC Faculdade do $A B C$ Av. Principe de Gales, 821 Santo André, SP, 09060-650, Brazil E-mail:caio_cintra@uol.com.br
} 